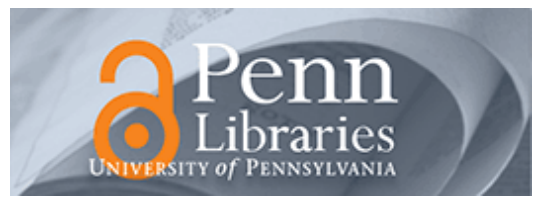

University of Pennsylvania

ScholarlyCommons

Finance Papers

Wharton Faculty Research

1990

\title{
Expectations and Volatility of Consumption and Asset Returns
}

Shmuel Kandel

Robert F. Stambaugh

University of Pennsylvania

Follow this and additional works at: https://repository.upenn.edu/fnce_papers

Part of the Finance Commons, and the Finance and Financial Management Commons

\section{Recommended Citation}

Kandel, S., \& Stambaugh, R. F. (1990). Expectations and Volatility of Consumption and Asset Returns.

Review of Financial Studies, 3 (2), 207-232. http://dx.doi.org/10.1093/rfs/3.2.207

This paper is posted at ScholarlyCommons. https://repository.upenn.edu/fnce_papers/327

For more information, please contact repository@pobox.upenn.edu. 


\title{
Expectations and Volatility of Consumption and Asset Returns
}

\begin{abstract}
We find that conditional means and variances of consumption growth vary through time, and this variation appears to be associated with the business cycle. A pricing model with fluctuating means and variances of consumption growth provides implications about conditional moments of returns for both short and long investment horizons, and these implications are explored empirically. The U-shaped pattern of first-order autocorrelations of returns, as well as business cycle patterns in the price of risk, appears to be consistent with the model, but our exploration suggests that other implications about conditional return moments are at odds with the data.
\end{abstract}

Disciplines

Finance | Finance and Financial Management 


\title{
EXPECTATIONS AND VOLATILITY OF
}

CONSUMPTION AND ASSET RETURNS*

by

Shmuel Fande1

Robert F. Stambaugh

Horking Paper No. 40/90

January 1990

\begin{abstract}
*Earlier vers
pectations and Volatility of Long-Horizor s cund necusus. sale aucususs ate gratefu1 to Stephen Brown, Wayne Ferson, Campbe11 Harvey, Joe1 Hasbrouck, James Poterba, Michae1 Rozeff, an anonymous referee, and participants in workshops at New York University, The University of Wisconsin, and the 1988 Johnson Symposium for helpful discussions and comments. The first author grateful1y acknowledges support from the Batterymarch Fellowship, the Center for Research in Security Prices, and the Institute for Business Research in Israe1, and both authors gratefully acknowledge support from the Institute for Quantitative Research in Finance.
\end{abstract}

This paper was partially financed by the Israel Institute of Business Research.

IIBR working papers are intended for preliminary circulation of tentative research results. Comments are we1come and should be addressed directly to the authors. 


\section{ABSTRACT}

We find that conditional means and variances of consumption growth vary through time, and this variation appears to be associated with the business cycle. A pricing model with fluctuating means and variances of consumption growth provides implications about conditional moments of returns for both short and long investment horizons, and these implications are explored empirically. The U-shaped pattern of first-order autocorrelations of returns, as well as business-cycle patterns in the price of risk, appear to be consistent with the model, but our exploration suggests that other implications about conditional return moments are at odds with the data.

Keywords: Business Cycle, Pricing Model, Consumption. 


\section{Introduction}

Much current empirical research on financial assets addresses the volatility and the predictability of rates of return. Two important and related questions are central to-this research: (i) Are the estimated properties of changes in investment opportunities consistent with equilibrium models of rational behavior? (ii) What macroeconomic effects, if any, are associated with changes in investment opportunities?

This exploratory study pursues an approach in which changes in the investment opportunity set are linked to changes in the conditional moments of consumption growth. In section 2, we begin our investigation empirically by identifying changes in the mean and the variance of the quarterly growth rate of real per capita consumption of nondurables and services. Both moments exhibit variation that appears to be related to the business cycle, in that recessions are typically accompanied by low expected growth and high volatility of growth.

We then turn in section 3 to consider the estimated properties of the consumption moments in a pricing model capable of providing various implications about asset returns over both short and long investment horizons. That objective is pursued in this study using the exchange-economy pricing framework of Lucas (1978), in which preferences are time-additive and exhibit constant relative risk aversion. Within this general pricing framework, we consider a model with an exogenously specified joint Markov process for the mean and the variance of consumption growth rates. This model, also analyzed in Kandel and Stambaugh (1989), has features similar to those in models developed by Mehra and Prescott (1985) and Abel (1988).

We analyze an example of the pricing model in which the Markov process for the consumption moments, along with the preference parameters, are chosen to reflect various features of the consumption and returns data. The 
transition probabilities of the Markov process are constructed to mimic the evolution through time of the conditional moments estimated in section 2 . Parameters are selected that calibrate the model to sample counterparts of the unconditional first and second moments of quarterly stock returns and consumption growth as well as the unconditional mean of the quarterly interest rate. Various other implications about changes in expected asset returns and volatilities are then provided by the model.

Section 4 analyzes estimated properties of expected returns and volatilities in the context of the implications provided by the example of the pricing model: For example, the pricing model implies that the firstorder autocorrelation of returns are negative and U-shaped with respect to investment horizon, and this pattern appears in the corresponding sample autocorrelations shown here and elsewhere [e.g., Fama and French (1988)]. Estimated conditional means and volatilities of stock returns are estimated for investment horizons of both one quarter and five years. Business cycles appear to play a role in the behavior of these moments as well as in the behavior of the price of risk. Some of the estimated relations between conditional return moments and conditional consumption moments appear to be consistent with the pricing model, such as the tendency for the price of risk to be high during recessions. In other cases, however, the estimated comovements in the moments appear to be at odds with the model.

Our objective in this study is not to add to the literature of formal tests of the intertemporal consumption-based asset pricing model, such as the tests of Hansen and Singleton (1982) and others. ${ }^{1}$ Most of these tests have tended to reject the standard intertemporal pricing model, at least when inferences are based on asymptotic distributions. These approaches, although

$1_{A}$ review of the results of these tests is provided by singleton (1987). 
econometrically rigorous, are sometimes limited in their ability to provide simple descriptions of the empirical characteristics of asset-return moments not accommodated by the model.

The analysis by Mehra and Prescott (1985) provides the latter type of description by focusing on the model's implications about an easily described moment of returns--the unconditional expected equity premium. In much the same spirit as Mehra and Prescott, we attempt to analyze implications of the pricing model by focusing on some easily described behaviors of moments of asset returns, except that we pursue this goal while examining conditional moments as well as unconditional moments.

Mehra and Prescott (1985) find that the standard Lucas model cannor yield a sufficiently large equity premium when relative risk aversion is restricted a priori to be less than ten. We do not restrict the value of this parameter but instead select a value that does in fact allow us to match, inter alia, the sample equity premium and average interest rate. We then ask whether the model, when so calibrated, appears to deliver empirically reasonable implications about other moments of returns. If a priori restrictions on this preference parameter are difficult to justify, as we suggest in section 3 , then our approach offers some easily described empirical challenges to the model that do not incorporate such a restriction.

This study explores relations between expected returns and volatilicy for long as well as short horizons. Returns for short horizons, such as one month, have been used in numerous studies to investigate the relation between expected excess returns and volatility. ${ }^{2}$ Fama and French $(1987,1988)$ provide

2 "Volatility," in this context, is used to denote either the variance or the standard deviation of the return. A partial list of the studies in this area includes Merton (1980), French, Schwert, and Stambaugh (1987), Poterba and Summers (1986), Gennotte and Marsh (1985), Hasbrouck (1985), Campbell (1987), and Bollerslev, Engle, and Wooldridge (1988). 
evidence illustrating how patterns in expected returns can become more apparent by examining returns over longer horizons. Although the observed patterns in expected returns may in fact be implied by models for short investment horizons (e.g., the equilibrium model analyzed here), or even by models estimated using short-horizon returns [e.g., the VAR model for monthly data estimated in Kandel and Stambaugh (1989)], the examination of longhorizon returns may help to provide clues useful in constructing such models. In this study we examine conditional volatility, as well as conditional expected returns, using long-horizons with a view towards exploring patterns that might be less apparent in short horizons.

\section{Estimating Conditional Expectations and Volatility of Consumption Growth}

In this section, we investigate changes in the mean and the variance of real per capita consumption growth. We use for this purpose the series of quarterly growth rates of real per capita consumption of nondurables and services constructed by Breeden, Gibbons, and Litzenberger (1989). ${ }^{3}$ This series covers the period from third quarter 1929 through the first quarter of 1982 and consists of a splicing of series constructed by different techniques, depending on the subperiod. From 1929 through 1938, the series is estimated by combining annual consumption data and monthly data on personal income, from 1939 through 1958 the series is based on quarterly consumption, and from 1959 through 1982 the series is based on monthly consumption.

The conditional expectation and the conditional standard deviation of consumption growth for quarter $t$ are modeled as linear functions of three financial variables observed at the end of quarter $[-1$ :

$\left(y_{B a a}-y_{A a a}\right)_{t-1}:$ the difference at the end of quarter $t-1$ between ${ }^{3}$ We thank Mike Gibbons for providing this data. 
Moody's average yield on bonds rated Baa and bonds rated Aaa.

$\left(y_{A a a}-y_{T B}\right)_{t-1}:$ the difference at the end of quarter $t-1$ between the Aaa yield and the yield on a U.S. Treasury Bill with maturity closest to one month.

$(\mathrm{D} / \mathrm{P})_{\mathrm{t}-1}$ : for the value-weighted portfolio of NYSE stocks, the ratio of dividends paid during the four quarters ending at quarter $t-1$ to the price at the end of quarter $t-1$.

These predictive variables are used by Fama and French (1987) to predict returns on stocks and bonds, and other researchers have found that similar variables also predict asset returns. For example, Rozeff (1984) finds that dividend-price ratios predict stock returns, and Keim and Stambaugh (1986) find that (among other variables) the difference in yields between low-grade bonds and Treasury Bills predicts stock and bond returns. Campbell (1987) shows that the slope of the (short-term) term structure can be used to predict stock returns. 4

Given that the above three financial variables and others like them appear to contain information about expected asset returns, we entertain the same variables here as possibly containing information about moments of consumption growth. Intertemporal consumption-based models of asset pricing generally possess the property that time-variation in moments of returns will be related to time-variation in the moments of consumption. We apply this concept here simply by using variables to predict consumption moments that

${ }^{4}$ Contemporaneous changes in similar variables have also been used as common risk factors in empirical investigations of multifactor pricing models. In the latter context, Chen, Roll, and Ross (1986) use return spreads between (i) low-grade and high-grade bonds and (ii) long-term high-grade bonds and Treasury Bills. 
have previously been found to contain information about expected asset returns. Some evidence regarding this general approach is found, for example, in Harvey (1988), who concludes that the term structure also contains information about expected consumption growth.

Let $c_{t}$ denote the continuously compounded growth rate in consumption for quarter $t$, and let $x_{t-1}$ denote a $3 \times 1$ vector of the above financial variables. We estimate the conditional expected growth rate of consumption from the regression

$$
c_{t}=\alpha_{0}+\alpha^{\prime} x_{t-1}+u_{t} .
$$

of course, the linear relation in (1) is only an approximation to what would almost surely be a nonlinear relation between the expected consumption growth rate and predetermined financial variables.

Hall (1978) and Hansen and Singleton (1983) present evidence that lagged consumption growth may be used in forcasting future consumption. In the quarterly series of consumption used here, the estimate of the first-order autocorrelation is high, 0.29, while higher-order autocorrelations are low. Breeden, Gibbons, and Litzenberger (1989) show that the high first-order autocorrelation of this series may be explained partially by a temporal aggregation bias--the bias associated with the reported quarterly consumption being the integral of the spot consumption rates during the quarter. The magnitude of the autocorrelations depends, of course, on the theoretical model of spot rates of consumption as well as the mechanism for reporting quarterly consumption. Several corrections for this bias have been suggested in the literature (see, for example, the discussions in Hall (1988), Grossman, Melino, and Shiller (1985), Singleton (1987), and Breeden, Gibbons, and Litzenberger (1989)]. In our investigation, as the set of lagged consumption 
growth rates is only a subset of the information available for the estimatation of the consumption moments, and as there is no single simple correction for the temporal aggregation bias, we do not include lagged consumption as a regressor. We do, however, adjust the standard errors of our coefficients to reflect the first-order autocorrelation induced by this bias.

The conditional standard deviation is modeled as a linear function of the same three predictive variables used above in the estimation of the conditional mean. That is, we estimate the standard deviation in a regression whose dependent variable is the absolute value of the residual from the regression in ( 1 , multiplied by a constant:

$$
(\sqrt{\pi / 2})\left|\hat{u}_{t}\right|=\beta_{0}+\beta \dot{x}_{t-1}+\varepsilon_{t}
$$

Davidian and Caroll (1987) conclude that estimates of standard deviations based on absolute-value transformations of residuals from the first regression are more robust to departures from conditional normality than are transformations in which the residuals are squared. Citing this evidence, Ferson and Harvey (1989) and Schwert and Seguin (1989) also use absolute residuals in estimating conditional standard deviations.

The system of equations in (1) and (2) is estimated using the Generalized Method of Moments (GMM), where the instruments consist of a constant and the elements in $x_{t-1}$. Since the same predictive variables are used in both (1) and (2), it can be shown that this GMM estimation is computationally equivalent to a two-stage procedure. ${ }^{5}$ OLS estimation of (1) is performed in the first stage, and the estimated residual from that regression, $\hat{u}$ ' is used in (2). OLS estimates of the parameters in (2) are then computed, and the

\footnotetext{
${ }^{5}$ A similar point is discussed by Hasbrouck $(1985,1986)$ and Campbell
} (1987). 
fitted values are the estimates of the conditional standard deviations.

Table 1 reports estimates of equations (1) and (2). The standard errors shown are based on the estimator of the covariance matrix proposed by Newey and West (1987). This estimator is applied here for the case of first-order autocorrelation of the residuals. Tests of the hypotheses that the conditional mean and the conditional volatility do not depend on the predictive variables produce chi-square statistics well above standard significance levels. The conditional mean is estimated in the first equation, and the coefficient on $(D / P)_{t-1}$ is reliably negative. In the second equation, used to estimate the conditional standard deviation, the coefficient on $\left(\mathrm{y}_{\mathrm{Baa}}-\mathrm{y}_{\mathrm{Aaa}}\right)_{\mathrm{t}-1}$ is reliably positive.

Figure 1 displays plots of the estimates of the conditional means and standard deviations of quarterly consumption growth. Also indicated in the figure are recessions as determined by the National Bureau of Economic Research [see Moore and Zarnowitz (1984)]. Both series appear to vary in relation to the business cycle. Troughs in the conditional mean tend to occur during recessions, towards the end of them. Peaks in the standard deviation tend to occur at the end of recessions or immediately after them. World War II is accompanied by a peak in the standard deviation and a trough in the mean.

\section{An Equilibrium Model with Time-Varying Moments of Consumption Growth}

\subsection{The General Framework}

The evidence in the previous section indicates that both the mean and the variance of consumption growth vary through time. In this section we describe an equilibrium model in which variation in these moments, when combined with the preferences of the representative investor, provide implications about variation in the moments of asset returns. Properties of this model are also 
analyzed in Kandel and Stambaugh (1989).

The basic framework of the model is that of Lucas (1978), to which we add features similar to those in the models of Mehra and Prescott (1985) and Abel (1988). The physical stock of capital is fixed, and aggregate consumption $c_{t}$ equals aggregate output in each period $t$. Let $\lambda_{t+1}$ denote unity plus the oneperiod growth rate in consumption, i.e., $\lambda_{t+1}-c_{t+1} / c_{t}$. Assume

(i) The consumer maximizes expected time-additive utility over an infinite horizon,

$$
\mathrm{E}\left\{\sum_{\tau=\mathrm{t}}^{\infty} \beta^{\tau-\mathrm{t}} \mathrm{U}\left(\mathrm{c}_{\tau}\right)\right\}, \quad 0<\beta<1,
$$

where the utility function exhibits constant relative risk aversion,

$$
U(c)=\frac{c^{1-\alpha}-1}{1-\alpha} \quad 0<\alpha<\infty .
$$

(ii) The logarithmic consumption growth rate, $\ln \left(\lambda_{t+1}\right)$, is distributed normally with mean $\mu_{t}$ and variance $\sigma_{t}^{2}$, conditional on information at time $t$.

(iii) The pair $\left(\mu_{t} \sigma_{\tau}^{2}\right)$ follows a joint stationary Markov process with a finite number of states, $S$. Let $s_{t}$ denote the state for $\left(\mu_{t} \sigma_{t}^{2}\right)$ at time $\tau$, where $s_{t}$ can take values $1, \ldots, s$. Let $\Phi$ denote the transition matrix with $(i, j)$ element

$$
\phi_{i j}=\operatorname{Prob}\left(s_{t+1}=j \mid s_{t}=i\right)
$$

(iv) Given $s_{t}$, the distribution of $s_{t+1}$ is independent of $\lambda_{t+1}$ (which is 
drawn from the distribution defined by $s_{t}$ ).

(v) Levered equicy is the claim on aggregate wealth net of a risky oneperiod bond that promises to pay, at time $t+1$, a fraction $\theta$ of aggregate wealth at time $t$.

The state of the economy follows a Markov process with the state represented as $(c, s), 0<c<\infty$ and $1 \leq s \leq S$, where, at time $t, c_{t}=c$ and $s_{t}-s$. The moments of returns, however, depend only on $s_{t}$ ' the state for $\left(\mu_{t} \sigma_{t}^{2}\right)$. The following propositions give interest rates and conditional moments of returns on levered equity. ${ }^{6}$

Proposition 1. Let $\mathrm{P}^{(\mathrm{FN})}$ denote the $\mathrm{S}$-vector of prices of the $\mathrm{N}$-period riskless claims in each of the $S$ states. Then

$$
p^{(F N)}=\Psi^{N} \iota_{S}
$$

where ${ }^{\prime} S$ is an $S$-vector of ones, $\Psi$ is the $S \times S$ matrix with $(i, j)$ element

$$
\psi_{i j}=\beta \phi_{i j} E\left(\lambda(i)^{-\alpha}\right),
$$

$\Psi^{N}$ denotes the Nth power of the matrix $\Psi$, and $\lambda(i)$ denotes the random growth

${ }^{6}$ Kandel and Stambaugh (1989) analyze additional properties of this model. In particular, they show that prices of aggregate wealth and levered equity are proportional to current consumption, with the proportionality factors depending only on $s_{t}$. Proofs of the propositions are available on request from the authors. 
rate drawn from the conditional distribution in which $s=i{ }^{7}$

Proposition 2. Let $\mathrm{E}^{(\mathrm{LN})}$ denote the $\mathrm{S}$-vector of conditional expected $\mathrm{N}$ period (simple) rates of return on levered equity in each of the $S$ states, $1 \leq \mathrm{s} \leq \mathrm{s}$.

$$
E^{(L N)}=\Gamma^{N} s^{2}{ }^{2} S
$$

where $\Gamma$ is an $S \times S$ matrix with $(i, j)$ element

$$
\gamma_{i j}=\frac{E\left(\max \left[0, \lambda(i)\left(1+w_{j}\right)-\theta w_{i}\right]\right)}{w_{i}-g_{i}}
$$

$w_{i}$ is the ith element of the S-vector $w$, given by

$$
w=(I-H)^{-1} H_{\iota}
$$

$H$ is the $S \times S$ matrix with $(i, j)$ element

$$
h_{i j}=\beta \phi_{i j} E\left\{\lambda(i)^{1-\alpha}\right\}
$$

$g_{i}$ is the $i^{\text {th }}$ element of the $S$-vector $g=Y_{\iota_{S}}$, and $Y$ is an SXS matrix with (i, j) element

7 Note that, given the assumption that $\ln [\lambda(i)]$ is normally distributed, for any $m, E\left(\lambda(i)^{m}\right)=\exp \left(\mu_{i} m+0.5 \sigma_{i}^{2} m^{2}\right)$, where $\mu_{i}$ and $\sigma_{i}^{2}$ denote the conditional mean and variance of $\ln [\lambda(i)]$. 


$$
y_{i j}=\beta \phi_{i j} E\left\{\min \left\{\lambda(i)^{1-\alpha}\left(1+w_{j}\right), \lambda(i)^{-\alpha} \theta w_{i}\right]\right\}
$$

Proposition 3. Let $\mathrm{V}^{(\mathrm{LN})}$ denote the vector of conditional variances of $\mathrm{N}$-period (simple) rates of return on levered equity in each of the $S$ states. Then $^{8}$

$$
v^{(L N)}=\equiv^{N}{ }^{2}-\left[\left(\Gamma^{N} \iota_{s}\right) *\left(\Gamma^{N} \iota_{s}\right)\right],
$$

where $\Xi$ is an SXS matrix with ( $i, j$ ) element

$$
\xi_{i j}=\phi_{i j} \frac{E\left(\left(\max \left[0, \lambda(i)\left(1+w_{j}\right)-\theta w_{i}\right]\right)^{2}\right)}{\left(w_{i}-g_{i}\right)^{2}}
$$

From the conditional moments provided in propositions 2 and 3 , we can easily obtain unconditional means and variances using $\pi$, the vector of steadystate probabilities:

$$
\begin{aligned}
& \bar{E}^{(L N)}=\pi^{\prime} E^{(L N)} \\
& \bar{V}^{(L N)}=\pi^{\prime} V^{(L N)}+\pi^{\prime}\left[\left(E^{(L N)}-\bar{E}^{(L N)}{ }_{\iota_{S}}\right) *\left(E^{(L N)}-\bar{E}^{(L N)} \iota_{S}\right)\right]
\end{aligned}
$$

Autocorrelations of returns for various horizons can also be obtained from the conditional moments. Let $R_{t, N}^{(L)}$ denote the $N$-period return on levered equity starting at the beginning of period $t$. In obtaining the first-order autocorrelation of $R_{t, N}^{(L)}, \operatorname{corr}\left(R_{t, N}^{(L)}, R_{t-N, N}^{(L)}\right.$, we note that

${ }^{8}$ The symbol $" *$ " denotes a Hadamard matrix product. If $\left[a_{i j}\right]$ and $\left[b_{i j}\right]$ denote the elements of $m \times n$ matrices, then $\left[a_{i j}\right] *\left[b_{i j}\right]-\left[a_{i j} \cdot b_{i j}\right]$. 


$$
\begin{aligned}
\operatorname{corr}\left(R_{t, N}^{(L)}, R_{t-N, N}^{(L)}\right) & =\frac{E\left[1+R_{t, 2 N}^{(L)}\right\}\left[E\left\{1+R_{t, N}^{(L)}\right\}\right]^{2}}{\operatorname{var}\left\{R_{t, N}^{(L)}\right\}}, \\
& =\frac{\bar{E}^{(L 2 N)}-2 \bar{E}^{(L N)}-\left[\bar{E}^{(L N)}\right]^{2}}{\bar{V}^{(L N)}}
\end{aligned}
$$

\subsection{An Example of the Model}

We construct a numerical example of the model in an attempt to capture some features of the time-varying behavior of the consumption moments estimated in section 2. In addition, we specify parameters of the model so as to match various unconditional moments of consumption growth and asset returns. Given the use of quarterly data in section 2, the example here is constructed so that a single period corresponds to one quarter. Quarterly returns data are used in the subsequent empirical analysis.

We assume a four-state process for $\left(\mu_{t} \sigma_{t}^{2}\right)$, the conditional moments of consumption growth. The tranisition matrix $\Phi$ is constructed in the following manner. For the estimated regression in (1), the 211 fitted quarterly values of expected consumption growth are separated into two groups--those less than the average fitted value and those greater. Likewise, the quarterly fitted standard deviations estimated in (2) are separated into two groups according to the average fitted standard deviation. Each quarter is then assigned to one of four states according to whether the two fitted moments for that quarter lie above or below their respective averages. The elements in each row of the transition matrix $\Phi$ are computed as the relative sample frequencies of moving from that state to each of the four states. The transition matrix so constructed is displayed in panel A of table 2.

The values of $\mu$ and $\sigma$ in each state are specified so that each parameter 
can take only two distinct values. That is, we specify two possible values of $\mu$ and two possible values of $\sigma$ and then assign the four possible combinations to one of the four staces. The relative ordering reflects the earlier construction of the states in computing the transition matrix. For example, the state with both the higher $\mu$ and the higher $\sigma$ corresponds to the quarters in which the fitted values of both parameters lie above their respective sample averages. The numerical values of $\mu$ and $\sigma$, reported in panel $A$ of table 2, are chosen to allow us to calibrate the model to a number of unconditional moment conditions.

We chose the two values of $\mu$ and the two values of $\sigma$, along with the preference parameters $\alpha$ and $\beta$ and the leverage parameter $\theta$, to match five sample moments estimated with quarterly data: (1) the average consumption growth rate, .0045 , (2) the standard deviation of the consumption growth rate, .0129 , (3) the average real return on the value-weighted NYSE index, 0.017 , (4) the standard deviation of the value-weighted NYSE return, 0.126 , and (5) the average real rate on a Treasury bill with maturity closest to one quarter, $-0.00054 .^{9}$ We were unable to match precisely the sample standard deviation of the real $T$-bill rate, 0.0146 ; the value for this parameter implied by the model is 0.0228 . Panel B of table 2 reports the above moments, both estimated in sample and implied by the model.

Other approaches to constructing the Markov process for $\left(\mu_{t} \sigma_{t}^{2}\right)$ could be pursued. For example, the method of Hamilton (1989) could be applied, in principle, to obtain maximum likelihood estimates of the parameters using only

${ }_{\text {Real returns are computed by deflating nominal returns by the quarterly }}^{9}$ inflation rate as measured by the Consumer Price Index. 
the univariate series of consumption growth rates. 10 we follow the procedure described here for several reasons. Our approach allows us to include the information about consumption moments apparently contained in the financial variables. Moreover, one of our objectives is to examine the relations between each of the consumption moments and the implied conditional moments of returns. With four states and only two values for each parameter, we can examine the effect of increases in one parameter while holding the other constant.

We must also emphasize that many choices of the values for $\mu$ and $\sigma$, although consistent with the desired (sample) unconditional mean and variance of consumption growth, do not permit choices of the remaining free parameters consistent with an equilibrium in which the unconditional return moments can be matched. In the example constructed here, $\beta=.9973, \theta=.478$, and $\alpha-55$. In other words, the pure rate of time preference is only slightly greater than zero, the debt/value ratio underlying the levered equity is slightly less than one-half, and relative risk aversion is high by traditional standards. The high value of $\alpha$ is essential to obtaining the both the desired equity premium and the interest rate in this model. ${ }^{11}$ For many choices of $\mu$ and $\sigma$, however, particularly those with larger differences between the two values of each parameter, an equilibrium with positive values of wealth in each state would

10 Cecchetti, Lam, and Mark (1988) estimate a two state version of a Markov process for consumption moments using this approach, but they constrain the variance to be the same in both states.

11 Althougn Mehra and Prescott (1985) do not emphasize the model's difficulty in producing a sufficiently low interest rate, it seems that this difficulty can be viewed as an integral part of the "puzzle" when risk aversion is constrained to be low. Moreover, the analysis of Weil (1989) indicates that high risk aversion is necessary to obtain both a sufficiently low interest rate and a sufficiently high equity premium even under some generalizations of preferences that allow independent parametrizations of risk aversion and the elasticity of intertemporal substitution. 
not exist for such a high value of $\alpha .^{12}$

Choices of $\alpha$ that are high by traditional standards are discussed by Kandel and Stambaugh (1989), and we will not duplicate that discussion here. We do observe, however, that the price of risk based on the unconditional moments implied by our example, with $\alpha=55$, is 1.08 . A central argument for a lower value of $\alpha$, cited by Mehra and Prescott (1985) and many others, relies on the approach of Friend and Blume (1975). They estimate the price of risk to be less than 2.0 and then divide this estimate by the fraction of aggregate wealth placed in risky assets (assumed to be between 0.5 and 0.8 ), obtaining an estimate of $\alpha$ between 2.0 and 3.0. However, this calculation is, in general, inappropriate when consumption growth rates are not independently and identically distributed. Ignoring the effects of changing conditional moments could lead one to infer, incorrectly, that the lower price of risk in our example implies a coefficient of risk aversion much lower than 55.13 Kandel and Stambaugh (1989) explain how ignoring the variability in consumption can lead one to infer, incorrectly, that a high value of $\alpha$ is inconsistent with patterns across countries in interest rates and average rates of consumption growth. They also observe that, while hypothetical gambles of large fractions of wealth seem to refute high values of $\alpha$, the assumption that relative risk aversion is constant over a wide range of wealth makes it possible to construct a gamble of some size that makes any given value of a seem unreasonable. As Kandel and Stambaugh note, however, it is difficult to gauge the extent to which the prominent implications of the pricing model hinge on the assumption that relative risk aversion is constant

12 Mehra and Prescott (1985) recognize that higher values of $\alpha$ can produce the desired equity premium and riskless rate but that these cases are more sensitive to the specification of the consumption process.

${ }^{13}$ A similar point is made by Kocherlakota (1988). 
over a wide range of wealth levels.

Instead of restricting the values of $\alpha$ or other unobservable parameters a priori, our approach is to choose parameters to match the unconditional means and variances listed earlier and then examine the resulting model's implications about other moments, such as conditional means and variances of equity returns.

\section{Changes in Expected Returns and Volatilities}

The example constructed in section 3 shows that, as long as the coefficient of relative risk aversion is not restricted, the model can produce an average equíty premium, an unconditional variance of equity, and an average riskfree rate that match the corresponding sample moments. In this section we explore empirically several of the model's implications about variation through time in moments of asset returns.

\subsection{Autocorrelations of Equity Returns for Short and Long Horizons}

Another set of unconditional moments that has been the focus of several recent empirical studies is the set of first-order autocorrelations of stock returns for short and long investment horizons. Using equation (17), we calculate the first-order autocorrelations of the returns on equity for investment horizons from 1 quarter to five years, as implied by the pricing model.

In Figure 2 we plot the first-order autocorrelations of equity returns as implied by the model as well as estimated using real holding-period returns on the value-weighted portfolio of NYSE stocks. The model's autocorrelations display a U-shaped pattern with respect to investment horizon; the autocorrelations are negative and decreasing up to a horizon of 8 quarters and increasing toward zero at longer horizons. This U-shapped pattern is 
consistent with the U-shaped pattern of negative first-order autocorrelations of equity returns with respect to investment horizons beyond one year as reported here and by Fama and French (1988) and Poterba and Summers (1989). The example of the model does not imply, however, the positive sample autocorrelations for investment horizons of two and three quarters. 14

\subsection{The Riskless Rate}

From propositions 1,2 and 3 , the equilibrium model also implies, in each state of the economy and for various investment horizons, values for the real riskless rate, the conditional expected excess equity return, and the conditional standard deviation of equity returns. Table 3 displays these conditional moments for horizons of one quarter and five years. Also shown is the implied price of risk for equity in each state, i.e., the ratio of mean excess return to variance.

As discussed in section 3 , the states of the economy relevant to determining conditional moments of asset returns are characterized by the first and second moments of consumption growth. Our exploration of the model's implications is based on this characterization. Consider first the one-quarter riskless rate. The model implies that this rate is increasing in mean consumption growth and decreasing in the standard deviation of consumption growth. To explore these implications, we use an instrumental variables technique to estimate the following errors-in-variables model:

$$
\mathrm{r}_{t+1}^{\mathrm{f}} \quad-\alpha_{0}+\alpha_{1} \cdot \hat{\mu}_{c t}+\alpha_{2} \cdot \hat{\sigma}_{c t}+u_{t+1,1},
$$

${ }^{14}$ We note that the sample estimates of the autocorrelations are based on simple returns (not continuously compounded). Overlapping observations are used in the same manner as Fama and French (1988), and the estimates are not bias adjusted. The statistical precision and reliability of sample autocorrelations of returns is considered by Fama and French (1988), Richardson (1988), and Cecchetti, Lam, and Mark (1989). 
where $\hat{\mu}_{c t}$, the estimated mean of quarter $t+1$ 's consumption growth rate, is the fitted value from the regression in equation (1), and $\hat{\sigma}_{c t}$, the estimated standard deviation of quarter $t+l$ 's consumption growth rate, is the fitted value from the regression in equation (2).

In addition to a vector of ones, two categorical variables are employed as instruments. The first variable equals unity if $\hat{\mu}_{c t}$ is less than the sample average of the fitted mean consumption growth rate, as estimated in equation (1), and zero otherwise. The second variable is unity if $\hat{\sigma}_{c t}$ is greater than the sample average of the fitted standard deviations, as estimated in equation (2), and zero otherwise. 15

The results of this estimation for the period from the third quarter of 1929 through the first quarter of 1982 are given in table 4. The standard errors are computed using the heteroskedasticity-consistent estimator of white (1980) and Hsieh (1983): A chi-square test does not reject the hypothesis that the coefficients for $\hat{\mu}_{c t}$ and $\hat{\sigma}_{c t}$ are equal to zero. However, the signs of the point estimates seem to be inconsistent with the model's implications. While the model implies that the real riskless rate is increasing in $\mu$ and decreasing in $\sigma$, neither estimated coefficient has the predicted sign; the coefficient for $\hat{\mu}_{c t}$ is negative and the coefficient for $\hat{\sigma}_{c t}$ is positive. The apparently contradictory behavior of the real race, at least the ex post rate examined here, is also evident from its time-series plot in figure 3. The largest peaks of this series occur during recessions, and the largest

15

The use of grouping based on the estimated moments of consumption for constructing the instrumental variables generally violates Wald's (1940) criterion for the success of this technique. Since the errors in our independent variables will be correlated with the instruments, the resulting coefficient estimators will still be inconsistent. Nevertheless, we adopt this instrumental variable approach in an effort to mitigate some of the bias that would be present in OLS estimators in the presence of errors in variables. 
troughs occur during expansions. ${ }^{16}$ As discussed in section 2, our estimates suggest that recessions are accompanied by low mean and high variance of consumption growth. Given this property, the pattern of the real rate is at odds not only with the numerical example of the model we analyze here, but also with any other parametrization of the Lucas framework that uses conditional moments of consumption as state variables.

Before proceeding, we should advise the reader that this estimation approach, which will be repeated below in exploring the variation in conditional moments of equity returns, is intended primarily as a device for describing in-sample comovements of fitted moments. We have also estimated variation in each of the moments of returns analyzed here in which the original three financial variables described in section 2 replace the fitted values $\hat{\mu}_{c t}$ and $\hat{\sigma}_{c t}$. Such regressions allow inferences in the absence of the error-in-variables problem inherent in the two-step procedure. In all cases, inferences about the null hypothesis of no variation in the conditional moment are identical to the inference based on the chi-square statistic reported below for each conditional moment examined. Moreover, the plots of fitted values obtained from the OLS regressions on the three financial variables closely resemble those displayed here.

\subsection{Expected Equity Premia}

We next consider the expected equity return in excess of the riskless rate (the equity premium). The implications about variation through time in the equity premium are explored in the same manner as the implications for the riskless rate. We estimate the relation

${ }^{16}$ Related evidence is reported by Ferson and Merrick (1987). 


$$
r_{t+1, N}=\beta_{0}+\beta_{1} \cdot \hat{\mu}_{c t}+\beta_{2} \cdot \hat{\sigma}_{c t}+u_{t+1, N}
$$

where the dependent variable is the excess return for the $\mathrm{N}$-quarter horizon starting at the beginning of quarter $t$. In the one-quarter estimation, $r_{t+1,1}$ is the return on the value-weighted portfolio of the New York Stock Exchange minus the yield on the U.S. Government security with maturity closest to 91 days, For the five-year estimation, we construct the excess return $r_{t+1,20}$ as the five-year holding-period return on the NYSE portfolio minus the compounded annual yield on the AAA bond described earlier in section 2. Table 4 reports the results of the estimations. The standard errors and test statistic in the five-year estimation are based on the heteroskedasticity-consistent Newey-West (1987) estimator of the covariance matrix incorporating autocorrelated disturbances for 19 lags.

The model implies that the equity premium for one quarter is increasing in $\mu$ and decreasing in $\sigma$. In the estimation of (21) for the one-quarter horizon, the signs of the coefficients for $\hat{\mu}_{c t}$ and $\hat{\sigma}_{c t}$ are consistent with the example's implications, but the chi-square statistic does not indicate that either of them is reliably nonzero.

In the estimation of (21) for the five-year horizon, the chi-square statistic rejects the hypothesis of zero coefficients for $\hat{\mu}_{c t}$ and $\hat{\sigma}_{c t}$ ( $p-$ value less than .01). The signs of the coefficients, however, are not as predicted. In the example of the model, the five-year equity premium is increasing in $\mu$ and decreasing in $\sigma$. On the other hand, the coefficient for $\hat{\mu}_{c t}$ is negative, and the coefficient for $\hat{\sigma}_{c t}$ is positive, although only the first of these coefficients lies more than two standard errors from zero.

Figure 4 displays the estimated equity premia for the five-year investment horizon. For comparison, we also plot the fitted values from the 
one-quarter estimation, although, as noted earlier, the coefficients for $\hat{\mu}_{c t}$ and $\hat{\sigma}_{c t}$ in that regression are not reliably different from zero. The estimated five-year equity premia exhibit a clear association with the business cycle, with recessions acccompanied by peaks in the series. A large peak in the series of five-year equity premia also occurs during World War II. (A similar but less pronounced pattern is found in the estimated one-quarter equity premia.) The plots support the inference suggested by the signs of the coefficient estimates for $\hat{\mu}_{c t}$ and $\hat{\sigma}_{c t}$ : given that recessions and World War II appear to be accompanied by low $\mu$ and high $\sigma$, and given that the model implies the five-year equity premium is increasing in $\mu$ and decreasing in $\sigma$, we see that the plotted behavior also appears to contradict the model's implications about variation in the equity premium.

\subsection{Standard Deviations of Equity Returns}

Conditional standard deviations of excess returns are estimated in a manner similar to that used in equation (2), except that $\hat{\mu}_{c t}$ and $\hat{\sigma}_{c t}$ are used as predictive variables along with the same instrumental variable approach described above. The conditional standard deviation of $r_{t+1, N}$ is estimated from the relation

$$
\sqrt{\pi / 2}\left|\hat{u}_{t+1, N}\right|=\beta_{0}+\beta_{1} \cdot \hat{\mu}_{c t}+\beta_{2} \cdot \hat{\sigma}_{t}+\varepsilon_{t+1, N}
$$

where $\hat{u}_{t+1, N}$ is the residual from (21). The results of this estimation are reported in table 4 .

For both one-quarter and five-year horizons, the chi-square statistic allows us to reject the hypothesis that the conditional standard deviation of returns is constant. The coefficient for $\hat{\mu}_{c t}$ is negative for both one- 
quarter and five-year horizons, although only the five-year coefficient is more than two standard errors from zero. The results for the five-year horizon appear to contradict the model, which, as shown in table 3 , implies that the standard deviation of equity returns is increasing in $\mu$. (The model's corresponding implication for the one-quarter standard deviation is ambiguous.) The model implies that the standard deviation of returns for both horizons is decreasing in $\sigma$. This prediction is consistent with the negative coefficient for $\hat{\sigma}_{c t}$ in the five-year estimation, although the coefficient is less than 1.5 standard errors from zero. On the other hand, the coefficient for $\hat{\sigma}_{c t}$ in the one-quarter estimation is positive and more than two standard errors above zero, contradicting the prediction of the model.

The fitted values from (22) can be interpreted directly as estimated conditional standard deviations of returns. Figure 5 plots these values for both one-quarter and five-year investment horizons. Recessions and World War II appear to accompanied by peaks in both series.

\subsection{The Price of Risk}

Finally, we turn our attention to the variation in the price of risk. Figure 6 displays, for both one-quarter and five-year horizons, the ratio of the equity premium estimated using (21) to the square of the conditional standard deviation estimated using (22). The one-quarter price of risk does not appear to be associated with the business cycle in any pronounced fashion. The model implies that the one-quarter price of risk is increasing in $\sigma$, but the model is ambiguous with respect to $\mu$.

The five-year price of risk appears to exhibit peaks diring recessions as well as during World War II. This business-cycle related variation is consistent with the implications of the model, when coupled with the estimated variation in the conditional moments of consumption growth. As reported in 
table 3 , the model implies that the five-year price of risk is decreasing in $\mu$ and increasing in $\sigma$. Thus, the peaks in the the price of risk during recessions are consistent with the estimated tendency for recessions to be accompanied by low $\mu$ and high $\sigma$.

We conclude with a test of the hypothesis that the price of risk is constant through time. The test is conducted by applying GMM to the twoequation system,

$$
\begin{gathered}
r_{t+1, N}=\lambda \cdot\left(\delta_{0}+\delta_{1} \hat{\mu}_{c t}+\delta_{2} \hat{\sigma}_{c t}\right)^{2}+\hat{\beta}_{1} \hat{\beta}_{c t}+\beta_{2} \hat{\sigma}_{c t}+u_{t+1, N} \\
\sqrt{\pi / 2}\left|u_{t+1, N}\right|=\delta_{0}+\delta_{1} \hat{\mu}_{c t}+\delta_{2} \hat{\sigma}_{c t}+\varepsilon_{t+1, N}
\end{gathered}
$$

where six orthogonality conditions are formed as the product of the disturbances in equations (23) and (24) with three instruments: a vector of ones and the two category variables used in the earlier IV estimation. This results in a just-identified model, and hypothesis that the price of risk is constant is equivalent to the condition $\left(\beta_{1} \beta_{2}\right)-\left(\begin{array}{ll}0 & 0\end{array}\right)$.

This estimation is conducted for both one-quarter and five-year horizons, and the statistic for testing $\left(\beta_{1} \beta_{2}\right)=\left(\begin{array}{ll}0 & 0\end{array}\right)$ is constructed using the NeweyWest estimator of the covariance matrix to reflect the appropriate number of lags (19 lags in the five-year case and 0 lags in the one-quarter case). Under the null hypothesis, the test statistic is asymptotically distributed $\chi^{2}$ with 2 degrees of freedom. For a five-year horizon, the test statistic is equal to 7.26 , which implies a p-value of 0.027 , thereby rejecting the hypothesis that the price of risk is constant. The one-quarter test produces a statistic equal to 0.36 with a p-value of 0.95 , thereby failing to reject 
the hypothesis that the one-quarter price of risk is constant. 17

\section{Conclusions}

Conditional means and standard deviations of quarterly consumption growth rates are estimated as linear functions of three predetermined financial variables. We can reject the hypotheses that the moments are constant, and the estimated moments appear to exhibit business-cycle effects. For much of the sample period, the estimated conditional mean growth rate is lowest during recessions, and the estimated conditional standard deviation of the growth rate is highest during recessions.

An equilibrium pricing model in which the mean and the variance of consumption growth follow a joint Markov process provides implications about moments of asset returns, both unconditional and conditional. We construct an example of the model in which the Markov process is constructed to mimic the variation in the estimated moments of consumption. Other parameters in the model are chosen to calibrate the model's implied unconditional moments of asset returns to equal the corresponding sample estimates.

The example of the model is then used to obtain implications about variation through time in moments of asset returns for investment horizons of various lengths. We examine these implications primarily using returns on the value-weighted NYSE index for investment horizons ranging from one-quarter to five-years. Estimates of first-order autocorrelations of returns for investmert horizons greater than one month are negative and $U$-shaped with respect to the length of the investment horizon. The model implies a similar pattern, with the implied autocorrelations for both one-quarter and two-year

17 Harvey (1989), using data after World War II, concludes that the onemonth price of risk is not constant. We also conducted our test for a onequarter horizon using post-war data and, consistent with Harvey's result, obtained a test statistic of 12.17 with a p-value less than 0.01 . 
returns matching almost exactly the sample estimates.

The estimated price of risk appears to vary through time and to exhibit a tendency to be high during recessions. The latter tendency appears to be more pronounced for five-year investment horizons, and we test and reject the hypothesis that the five-year price of risk is constant. The tendency for the price of risk to be high during recessions, coupled with previously estimated variation in the moments of consumption, appears to be consistent with the implications of the equilibrium model. The model implies that the price of risk should be decreasing in mean consumption growth and increasing in the volatility.

We detect reliable variation in conditional means and standard deviations of five-year returns, and the fitted values of both moments tend to be high during recessions. The latter tendency appears to be inconsistent with the implications of the model, in that the model implies that both return moments should be increasing in expected consumption growth and decreasing in the volatility of consumption growth. 


\section{REFERENCES}

Abel, Andrew B., 1988, "Stock Prices under Time-Varying Dividend Risk: An Exact Solution in an Infinite-Horizon General Equilibrium Model, " Journal of Monetary Economics 22, 375-394.

Bollerslev, Tim, Robert F. Engle, and Jeffrey M. Wooldridge, 1988, "A Capital Asset Pricing Model with Time-varying Covariances," Journal of Political Economy $96,116-131$.

Breeden, Douglas T., Michael R. Gibbons, and Robert H. Litzenberger, 1989, "Empirical Tests of the Consumption-Oriented CAPM," The Journal of Finance $44,231-262$.

Campbe11, John Y., 1987, "Stock Returns and the Term Structure," Journal of Financial Economics 18, 373-399.

Cecchetti, Stephen G., Pok-sang Lam, and Nelson C. Mark, 1988, "Mean Reversion in Equilibrium Asset Prices," Working paper, Ohio State University.

Chen, Nai-Fu, Richard Roll, and Stephen A. Ross, 1986, "Economic Forces and the Stock Market," Journal of Business 59, 383-403.

Davidian, M. and R. J. Carroll, 1987, "Variance Function Estimation," Journal of the American Statistical Association 82, 1079-1091.

Fama, Eugene F. and Kenneth R. French, 1987, "Forecasting Returns on Corporate Bonds and Common Stocks," Working Paper, University of Chicago.

Fama, Eugene F. and Kenneth R. French, 1988, "Permanent and Temporary Components of Stock Prices," Journal of Political Economy 96, 246-273.

Ferson, Wayne E. and Campbell R. Harvey, 1989, "Variation of Economic Risk Premiums," working paper, University of Chicago.

Ferson, Wayne E. and John J. Merrick, Jr., 1987, "Nonstationarity and Stage-of the-Business-Cycle Effects in Consumption-Based Asset Pricing Relations," Journal of Financial Economics 18, 127-146.

French, Kenneth R., G. William Schwert, and Robert F. Stambaugh, 1987, "Expected Stock Returns and Volatility," Journal of Financial Economics $19,3-29$.

Friend, Irwin and Marshall E. Blume, 1975, "The Demand for Risky Assets," American Economic Review 65, 900-922.

Grossman, S.J., A. Melino, R.J. Shiller, 1985, "Estimating the Continuous Time Consumption Based Asset Pricing Model," NBER Working Paper.

Hall, Robert E., 1978, "Stochastic Implications of the Life Cycle-Permanent Income Hypothesis: Theory and Evidence," Journal of Political Economy 86, $971-988$.

Hall, Robert E., 1988, "Intertemporal Substitution in Consumption," Journal 
of Political Economy $96,339-357$.

Hamilton, James D., 1989. "A New Approach ta the Economic Analysis of Nonstationary Time Series and the Business Cycle," Econometrica 57, 357 384 .

Hansen, Lars Peter, 1982, "Large Sample Properties of Generalized Method of Moment Estimators," Econometrica 50, 1029-1054.

Hansen, Lars Peter and Kenneth J. Singleton, 1982, "Generalized Instrumental Variables Estimation of Nonlinear Rational Expectations Models," Econometrica 50, 1269-1286 (with corrections in Econometrica 52, 267 268).

Hansen, Lars Peter and Kenneth J. Singleton, 1983, "Stochastic Consumption, Risk Aversion, and the Temporal Behavior of Asset Returns," Journal of Political Economy $91,249.265$.

Harvey, Campbell R., 1988, "The Real Term Structure and Consumption Growth," Journal of Financial Economics 22, 305-333.

Harvey, Campbell R., 1989, "Is the Expected Compensation for Market Volatility Constant Through Time?" working paper, Duke University.

Hasbrouck, Joel, 1985, "Ex Ante Risk Premia and Ex Post Variance in Linear Return Models: An Econometric Analysis," working paper, New York University (New York, NY).

Hasbrouck, Joel, 1986, "On the Estimation of Linear Heteroskedasticity Models," working paper, New York University (New York, NY).

Hsieh, David A., 1983, "A Heteroscedasticity-Consistent Covariance Matrix Estimator for Time Series Regressions," Journal of Econometrics 22, 281 290.

Kandel, Shmuel and Robert F. Stambaugh, 1989, "Modeling Expected Stock Returns for Long and Short Horizons," working paper, University of Chicago (Chicago, IL) and lniversity of Pennsylvania (Philadelphia, PA).

Keim, Donald B. and Robert F. Stambaugh, 1986, "Predicting Returns in the Stock and Bond Markets," Journal of Financial Economics 17, 357-390.

Kocherlakota, Narayana R., 1988, "In Defense of the Time and State Separable Utility-Based Asset Pricing Model," working paper, Northwestern University.

Lucas, Robert E. Jr., 1978, "Asset Prices in an Exchange Economy," Econometrica $46,1429-1445$.

Mehra, Rajnish and Edward C. Prescott, 1985, "The Equity Premium: A Puzzle," Journal of Monetary Economics 15, 145-162.

Merton, Robert C., 1980, "On Estimating the Expected Return on the Market: An Exploratory Investigacion," Journal of Financial Economics 8, 323-361. 
Moore, Geoffrey and Victor Zarnowitz, 1984, "The Development and Role of the National Bureau's Business Cycle Chronologies," working paper, National Bureau of Economic Research (Cambridge, MA).

Newey, Whitney K. and Kenneth D. West, 1987, "A Simple, Positive SemiDefinite, Heteroskedasticity and Autocorrelation Consistent Covariance Matrix," Econometrica 55, 703-708.

Poterba, James A. and Lawrence H. Summers, 1986, "The Persistence of Volatility and Stock Market Fluctuations, " American Economic Review 76, $1142-1151$.

Richardson, Matthew, 1988, "Temporary Components of Stock Prices: A Skeptic's View," Working paper, Stanford University.

Rubinstein, Mark, 1974, "An Aggregation Theorem for Securities Markets," Journal of Financial Economics 1, 225-244.

Schwert, G. William, 1987, "Why Does Stock Market Volatility Change Over Time?" working paper, University of Rochester (Rochester, NY).

Schwert, G. William and Paul J. Seguin, 1989, "Heteroskedasticity in Stock Returns," working paper, University of Rochester.

Singleton, Kenneth J., 1987, "Specification and Estimation of Intertemporal Asset Pricing Models," working paper, Carnegie-Mellon University.

White, Halbert, 1980, "A Heteroskedasticity-Consistent Covariance Matrix Estimator and a Direct Test for Heteroskedasticity, " Econometrica' 48, 817-838. 
Estimation of Conditional Means and Standard Deriations of Quarterly Consumpion Growth Rates

$(1929 /$ III - 1983/I)
(I) $c_{t+1}$
$-\beta_{0}+\beta_{1} \cdot\left(\mathrm{y}_{\mathrm{Baa}}{ }^{-\mathrm{y}_{\mathrm{Aaa}}}\right)_{\tau}+\beta_{2} \cdot\left(\mathrm{y}_{\mathrm{Aaa}}-\mathrm{y}_{\mathrm{TB}}\right)_{t}+\beta_{3} \cdot(\mathrm{D} / \mathrm{P})_{\mathrm{t}}+\mathrm{u}_{\mathrm{t}+1}$
(II)
$\sqrt{\pi / 2}\left|\hat{u}_{\tau+1}\right|=\beta_{0}+\beta_{1} \cdot\left(\mathrm{y}_{\mathrm{Baa}}-\mathrm{y}_{\mathrm{Aaa}}\right)_{\tau}+\beta_{2} \cdot\left(\mathrm{y}_{\mathrm{Aaa}}-\mathrm{y}_{\mathrm{TB}}\right)_{t}+\beta_{3} \cdot(\mathrm{D} / \mathrm{P})_{t}+\eta_{t+1}$

Estimated coefficients (standard errors in parentheses)

\begin{tabular}{lcccccc} 
Equation & $\beta_{0}$ & $\beta_{1}$ & $\beta_{2}$ & $\beta_{3}$ & adj. $R^{2}$ & $\chi^{2^{c}}$ \\
\hline I. & 0.01035 & -0.01081 & 0.12152 & -0.18413 & 0.032 & $\begin{array}{c}\text { (0.20 } \\
\end{array}$ \\
& $(0.00334)$ & $(0.22935)$ & $(0.08711)$ & $(0.07622)$ & & $(0.03)$ \\
II. & -0.00041 & 0.27024 & 0.17300 & 0.09657 & 0.156 & 27.44 \\
& $(0.00251)$ & $(0.18548)$ & $(0.07766)$ & $(0.05246)$ & & $(0.00)$ \\
\hline
\end{tabular}

aThe variables are defined as follows. $c_{t+1}: \begin{aligned} & \text { the growth rate in real per capita consumption } \\ & \text { (nondurables plus services) for quarter } t+1\end{aligned}$

$\left(y_{\mathrm{Baa}}-\mathrm{y}_{\mathrm{Aaa}}\right)_{\tau}$ : the difference at the end of quarter $t$ between Moody's average yield on bonds rated Baa and bonds rated Aaa.

$\left(y_{A a a}-y_{T B}\right)_{t}$ : the difference at the end of quarter $t$ between the Aaa yield and the yield on a U.S. Treasury Bill with maturity closest to one month.

$(D / P)_{t}$ : for the value-weighted portfolio of NYSE stocks, the ratio of dividends paid in quarters t-3 through quarter $t$ to the price at the end of quarter $t$.

${ }^{b}$ The coefficients are estimated using ordinary least squares, and the standard errors and test statisitics are based on the estimator of the covariance matrix proposed by Newey and west (1987), where one lag is used in adjusting for autocorrelation in the residuals.

$c^{c}$ The statistic reported is asymptotically distributed as $\chi^{2}$ with three degrees of freedom under the null hypothesis that all of the coefficients on the independent variables (excluding the intercept) are equal to zero. The pvalue is shown in parentheses. 
Table 2

Properties of the Example of the Equilibrium Model

A. Markov Process for the Conditional Mean and Standard Deviation of the Quarterly Consumption Growth Rate

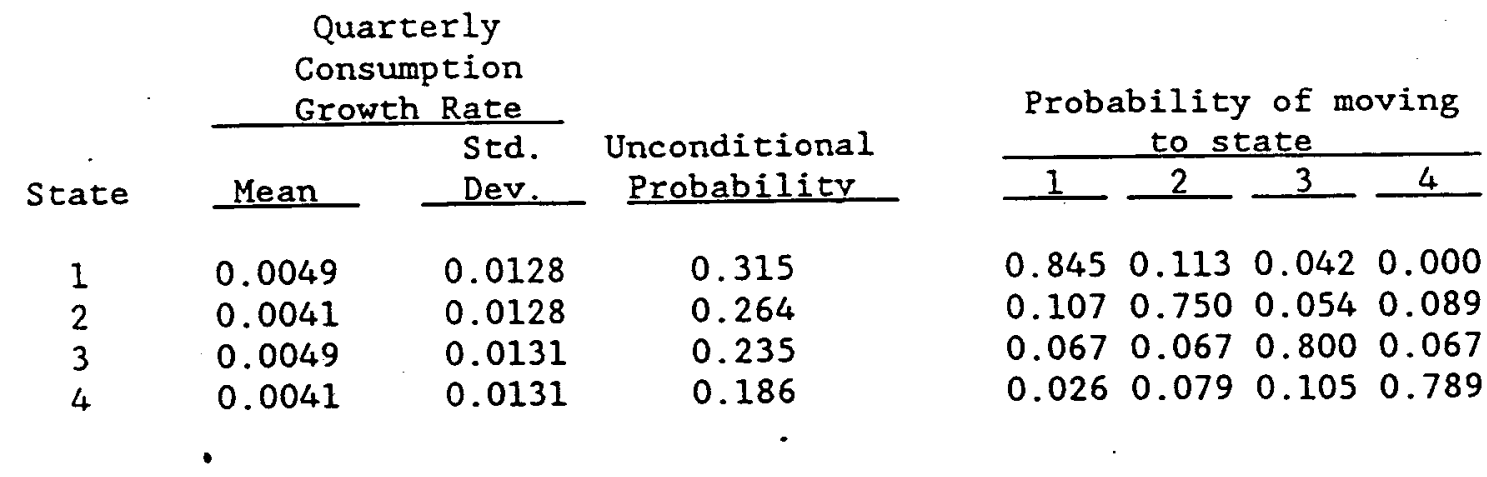

B. Unconditional Moments of Consumption Growth and Asset Returns

\begin{tabular}{|c|c|c|c|c|}
\hline \multirow[b]{2}{*}{ Quantity } & \multicolumn{2}{|c|}{$\begin{array}{l}\text { Implied by }{ }^{a} \\
\text { the Model }\end{array}$} & \multicolumn{2}{|c|}{$\begin{array}{l}\text { Sample }{ }^{b} \\
\text { Values }\end{array}$} \\
\hline & Mean & $\begin{array}{l}\text { Std. } \\
\text { Dev. }\end{array}$ & Mean & $\begin{array}{l}\text { Std. } \\
\text { Dev. }\end{array}$ \\
\hline $\begin{array}{l}\text { mption Growth Rate } \\
\text { of Return on a }\end{array}$ & 0.00453 & 0.01292 & 0.00452 & 0.01292 \\
\hline skless Asset & -0.00055 & 0.02284 & -0.00054 & 0.01464 \\
\hline $\begin{array}{l}\text { or keturn on } \\
\text { uity }\end{array}$ & 0.01713 & 0.12578 & 0.01727 & 0.12563 \\
\hline
\end{tabular}

$a_{\text {The model }}$ is calibrated with the consumption process of panel $\mathrm{A}$, a leverage ratio of $\theta=.478$, and preference parameters $\alpha=55$ and $\beta=.99731$.

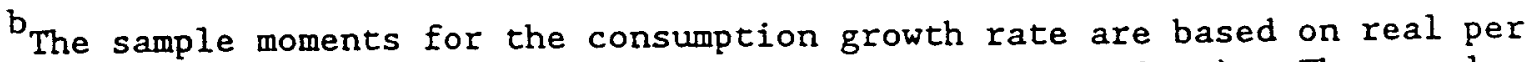
capita rates of growth of consumption (nondurables and services). The sample moments for the riskless asset are based on one-quarter real rates of return (yield less the inflation rate) on U.S. Treasury Bills with maturity closest to three months. The sample moments for equity are based on real returns on the value-weighted portfolio of N.YSE stocks. 


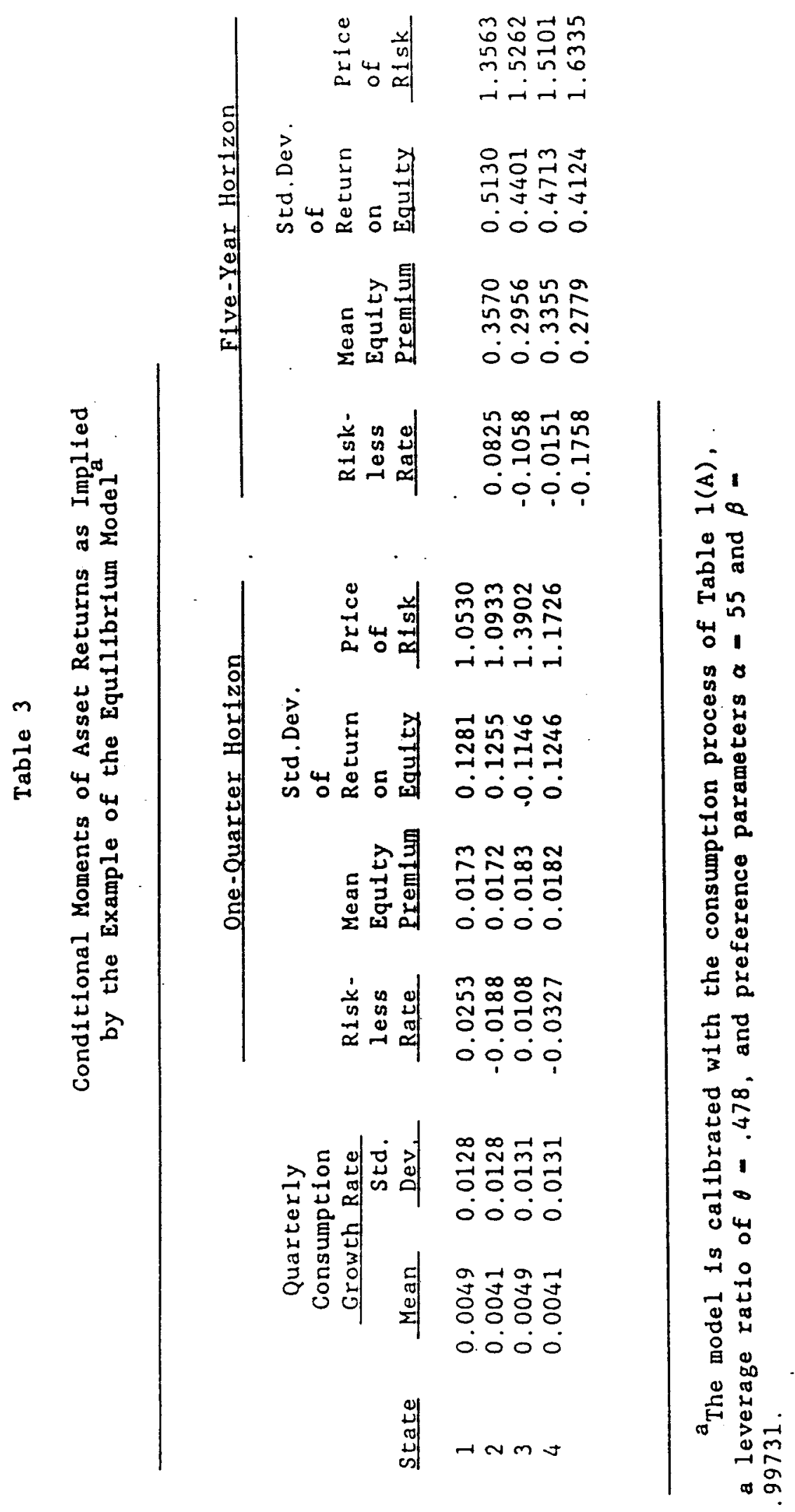


Table 4

Instrumental Variables Estimation of Conditional Expected Returns and Standard Deviations
(I) $\quad r_{t+1}^{f}$
$-\beta_{0}+\beta_{1} \cdot \hat{\mu}_{c t}+\beta_{2} \cdot \hat{\sigma}_{c t}+u_{t+1,1}$
(II) $r_{t+1,1}$
$=\beta_{0}+\beta_{1} \cdot \hat{\mu}_{c t}+\beta_{2} \cdot \hat{\sigma}_{c t}+u_{t+1,1}$
(III) $\sqrt{\pi / 2}$
$\left|\hat{u}_{t+1,1}\right|=\beta_{0}+\beta_{1} \cdot \hat{\mu}_{c t}+\beta_{2} \cdot \hat{\sigma}_{t}+\varepsilon_{t+1,1}$
(IV) $r_{t+1,20}$
$=\beta_{0}+\beta_{1} \cdot \hat{\mu}_{c t}+\beta_{2} \cdot \hat{\sigma}_{c t}+u_{t+1,20}$
(v) $\sqrt{\pi / 2}\left|\hat{u}_{t+1,20}\right|=\beta_{0}+\beta_{1} \cdot \hat{\mu}_{c t}+\beta_{2} \cdot \hat{\sigma}_{t}+\varepsilon_{t+1,20}$

Estimated coefficients (standard errors in parentheses) ${ }^{a}$

$\begin{array}{ccccc}\text { Equation } & \beta_{0} & \beta_{1} & \beta_{2} & \chi^{2^{b}} \\ \text { I. } & -0.00170 & -0.21863 & 0.19817 & 0.58 \\ & 0.00337 & 0.42798 & 0.29765 & (0.75) \\ \text { II. } & -0.00497 & -0.03972 & 2.12435 & 0.68 \\ & (0.02632) & (3.62074) & (2.73426) & (0.71) \\ \text { III. } & 0.03412 & -4.90030 & 8.22215 & 13.99 \\ & (0.02162) & (2.95201) & (2.20296) & (0.00) \\ \text { VI. } & 1.04353 & -137.34302 & 1.42524 & 27.88 \\ & (0.31003) & (28.49148) & (16.24747) & (0.00) \\ \text { V. } & 0.64126 & -25.31930 & -11.24836 & 7.48 \\ & (0.12467) & (10.05942) & (9.81230) & (0.02)\end{array}$

The coefficients are estimated using the instrumental variables

technique. The standard errors and test statistics in equations $I, I I$, and III are based on the heteroskedasticity-consistent estimator of the covariance matrix proposed by white (1980) and Hsieh (1983). Those in equations IV and V are based on the estimator of the covariance matrix proposed by Newey and West (1987) computed to reflest 19 autocorrelated lags.

The data are from the period 1929-III through 1982-I. The variables are defined as follows: 
$r_{t}^{f}$ : the one-quarter real rate of return (the yield at the beginning of the quarter less the inflation rate) on a U.S. Treasury security with maturity closest to three months.

$r_{t, N}$ : the excess rate of return on the value-weighted portfolio of NYSE stocks for the $\mathrm{N}$-quarter horizon starting at the beginning of quarter $t$. For $N-1$, the return is in excess of the yield on a the three month U.S. Treasury security; for $\mathrm{N}-20$, the return is in excess of the compounded annual yield on a long-term AAA bond.

$\hat{\mu}_{c t}:$ the estimated mean of quarter $t+1$ 's consumption growth rate. The estimator is the fitted value from the regression in table 1 , equation $I$.

$\hat{\sigma}_{c t}:$ the estimated standard deviation of quarter $t+1$ 's consumption growth rate. The estimator is the fitted value from the regression in table 1, equation II.

In addition to a vector of ones, two categorical variables are employed as instruments. The first variable equals unity if $\hat{\mu}_{c t}$ is less than the sample average of the fitted mean consumption growth rate, as estimated in equation ( 1 ), and zero otherwise. The second variable is unity if $\hat{\sigma}_{c t}$ is greater than the sample average of the fitted standard deviations, as estimated in equation (2), and zero otherwise.

$b$ The statistic reported is asymptotically distributed as $\chi^{2}$ with two degrees of freedom under the null hypothesis that the coefficients for $\hat{\beta}_{c t}$ and $\hat{\sigma}_{c t}$ are equal to zero. The $p$-value is shown in parentheses. 


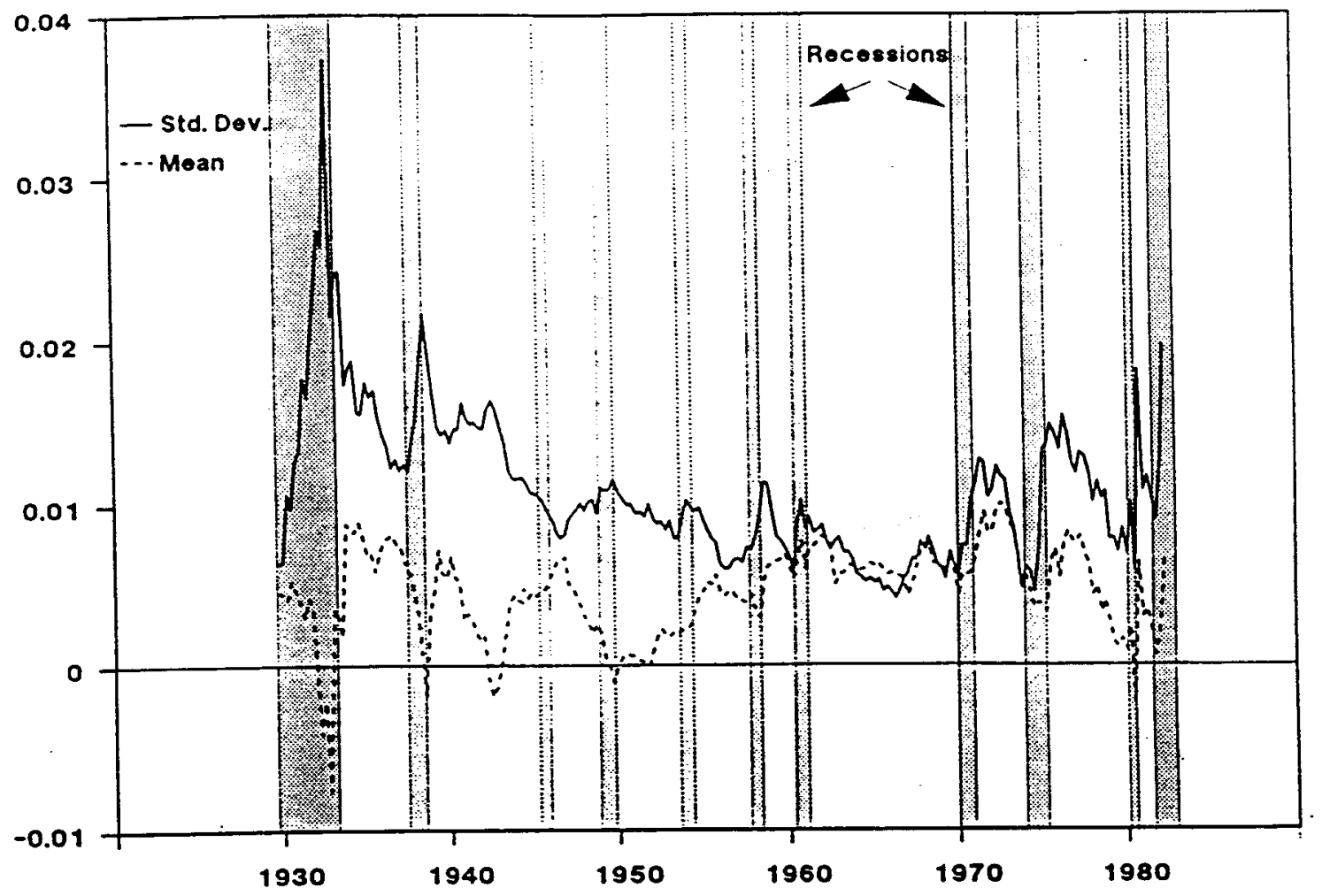

Figure 1. Estimated means and standard deviations of quarterly growth rates of consumption (nondurables and services). 


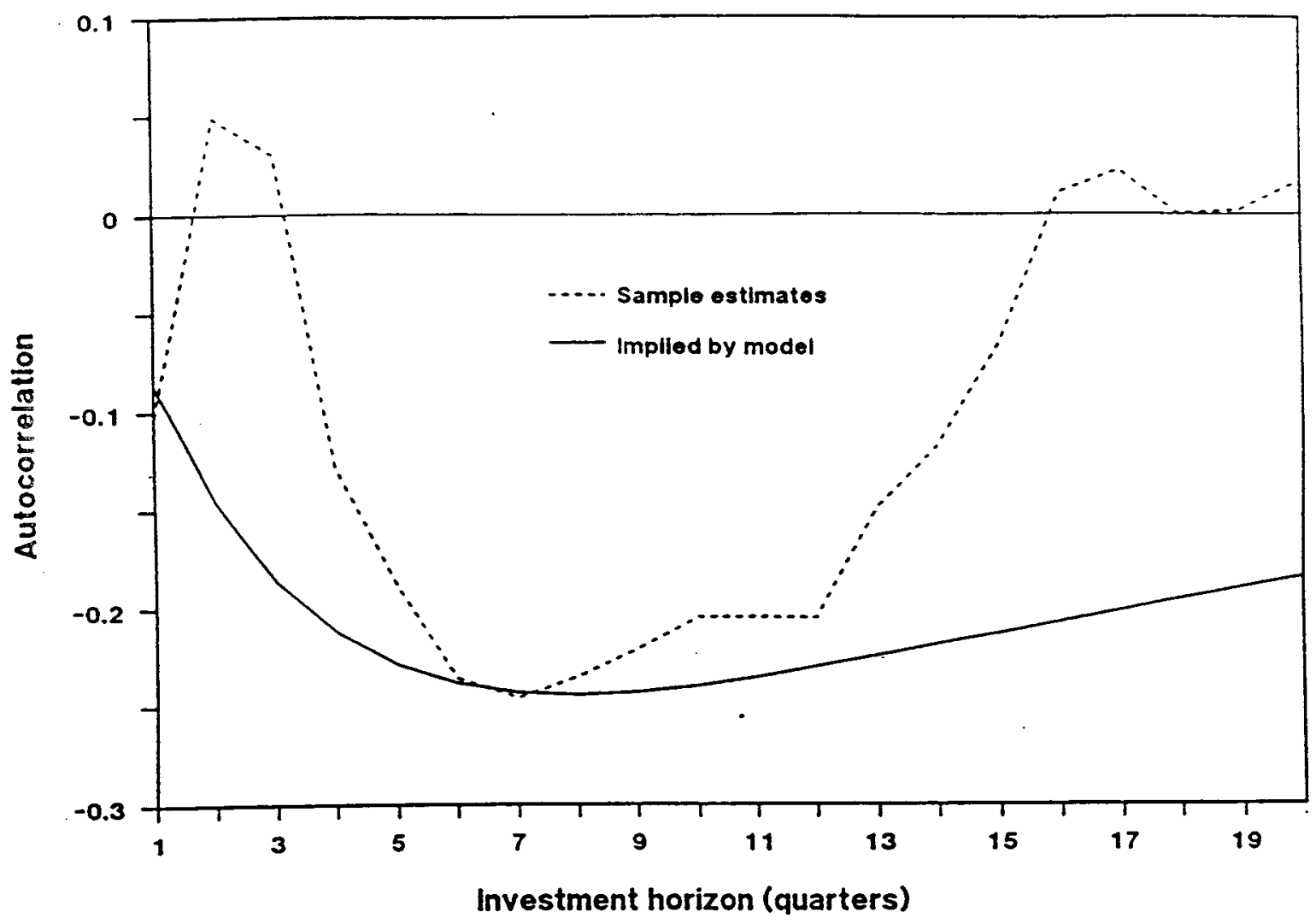

Figure 2. First-order autocorrelations of equity returns for various investment horizons. The solid line plots the values implied by the equilibrium model, and the dashed line plots estimates computed with simple returns on the value-weighted portfolio of the New York Stock Exchange. 


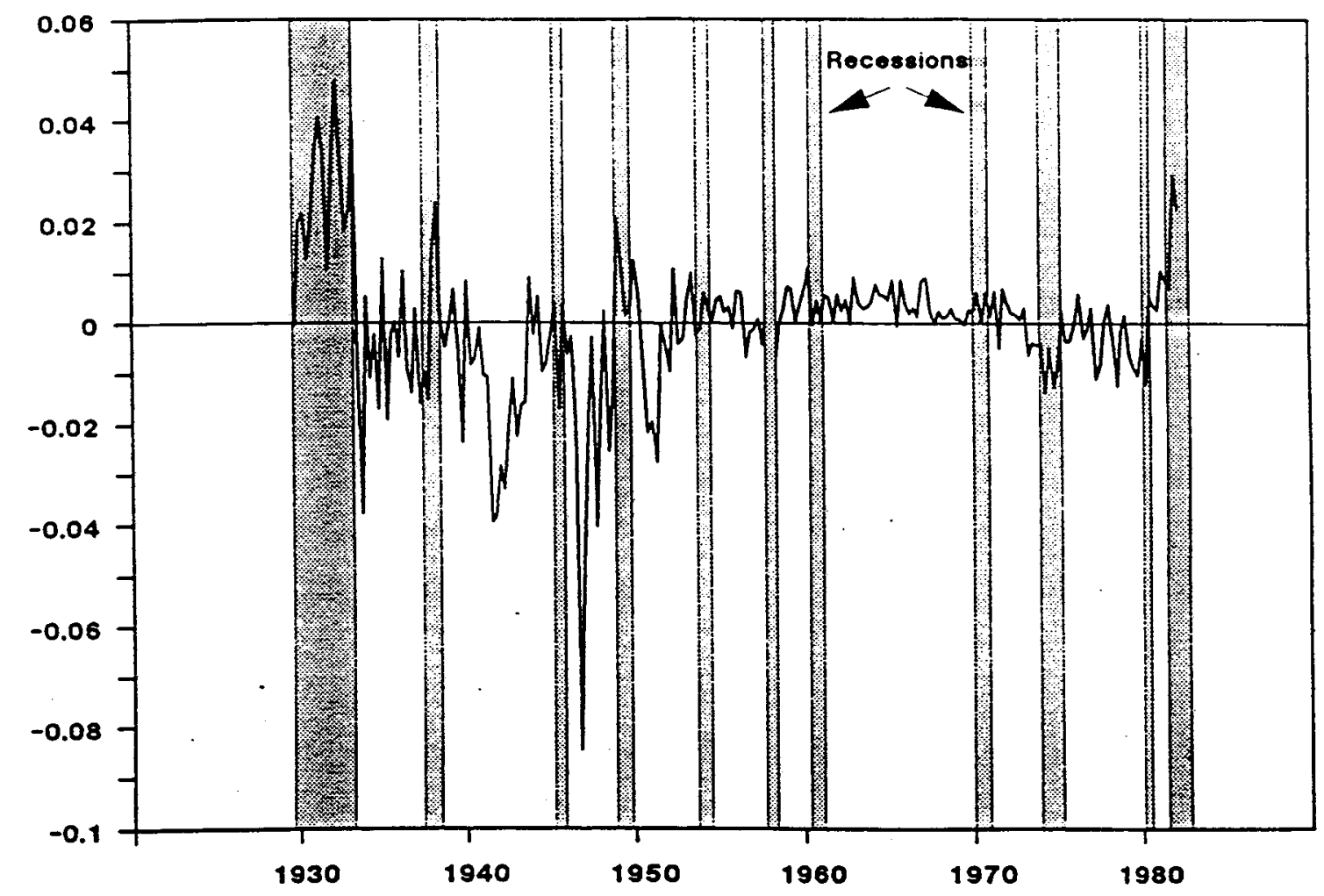

Figure 3. Quarterly real rates of return on U.S. Treasury bills. The value plotted is the nominal yield on the T-bill with maturity closest to 91 days deflated by the inflation rate of the Consumer Price Index. 


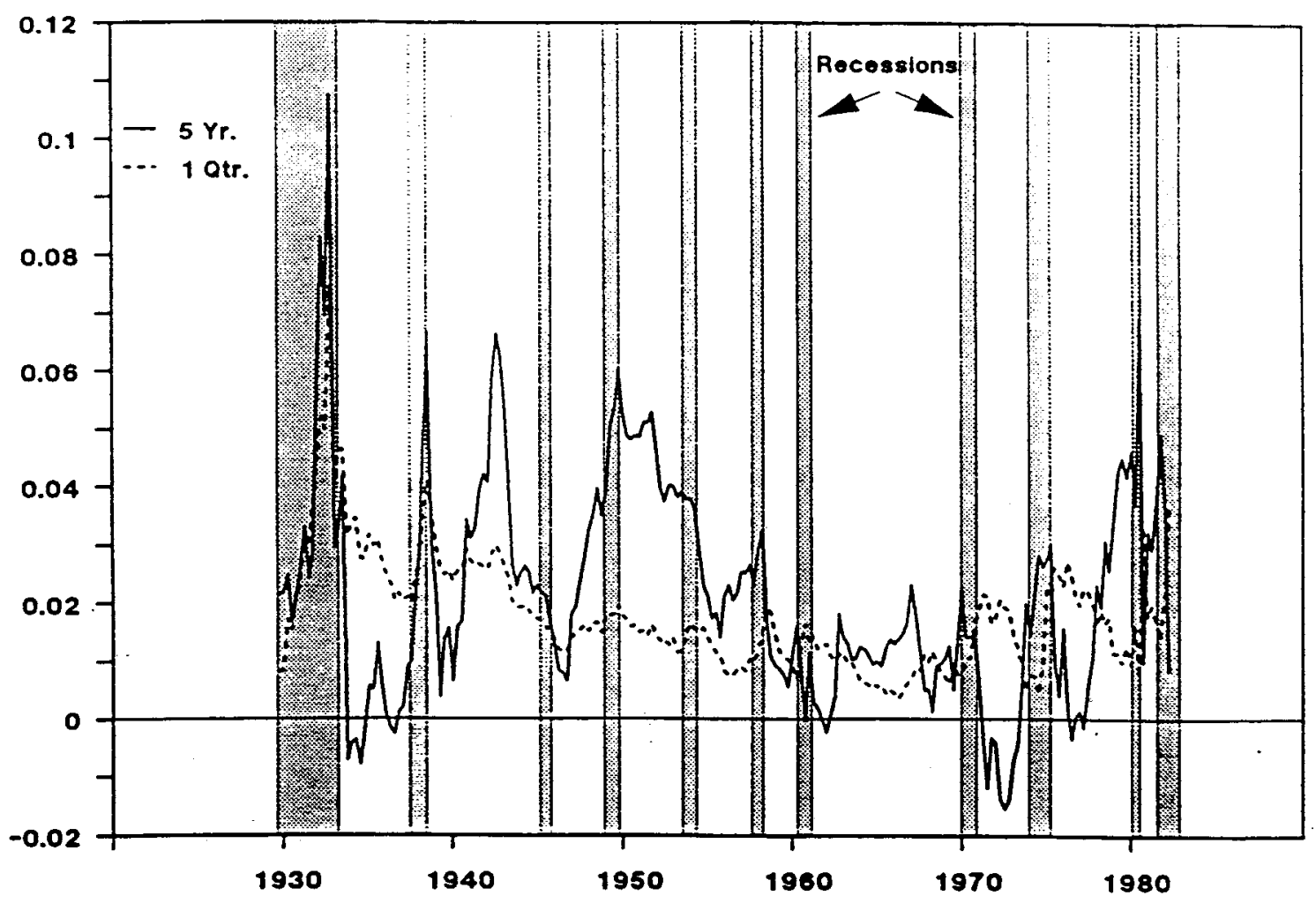

Figure 4. Estimated expected excess returns on the value-weighted portfolio of the New York Stock Exchange for investment horizons of one quarter (dashed line) and five years (solid line). The five-year value is divided by 20 , so that both series are plotted as quarterly values. 


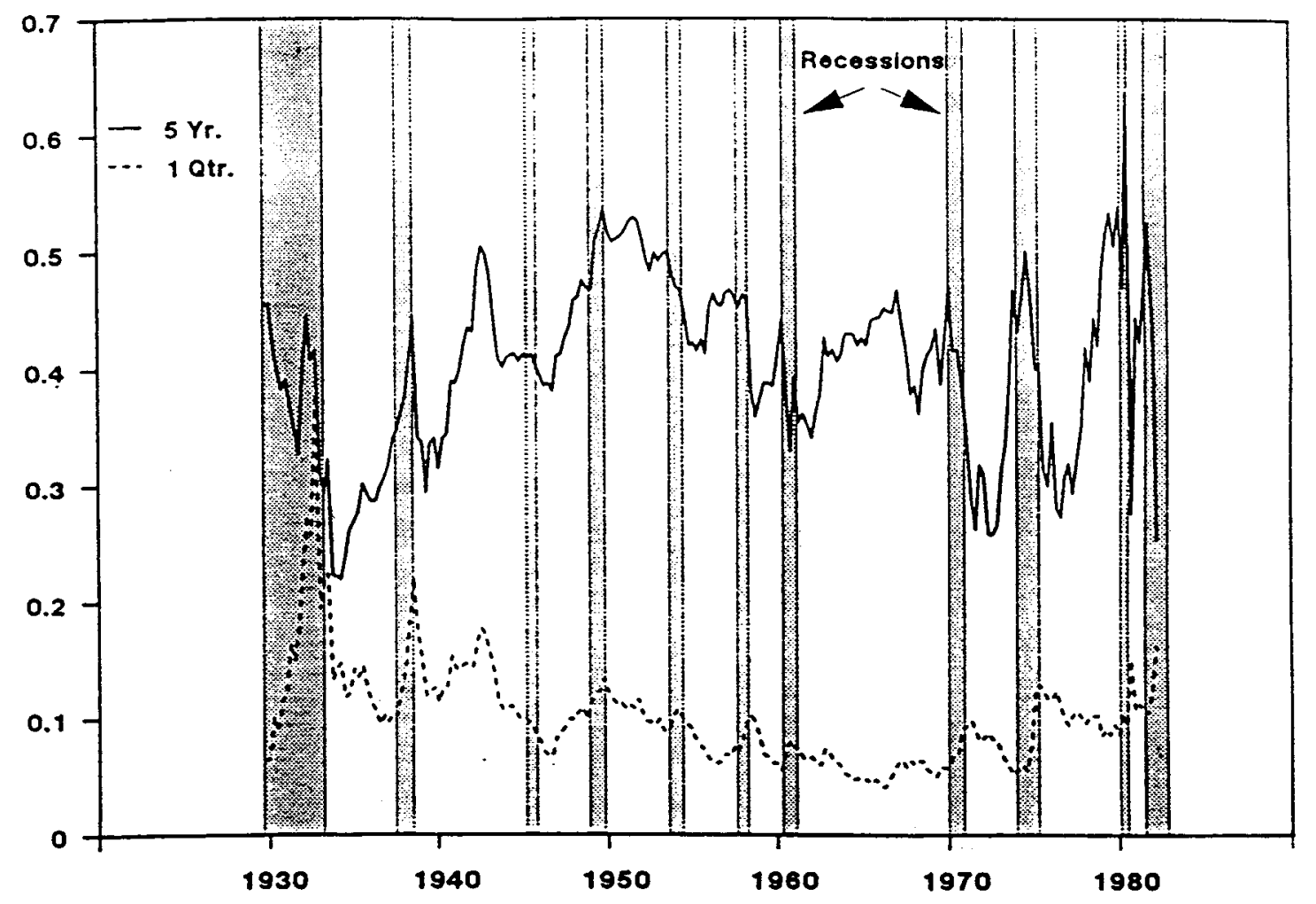

Figure 5. Estimated standard deviations of excess returns on the valueweighted portfolio of the New York Stock Exchange for investment horizons of one quarter (dashed line) and five years (solid line). 


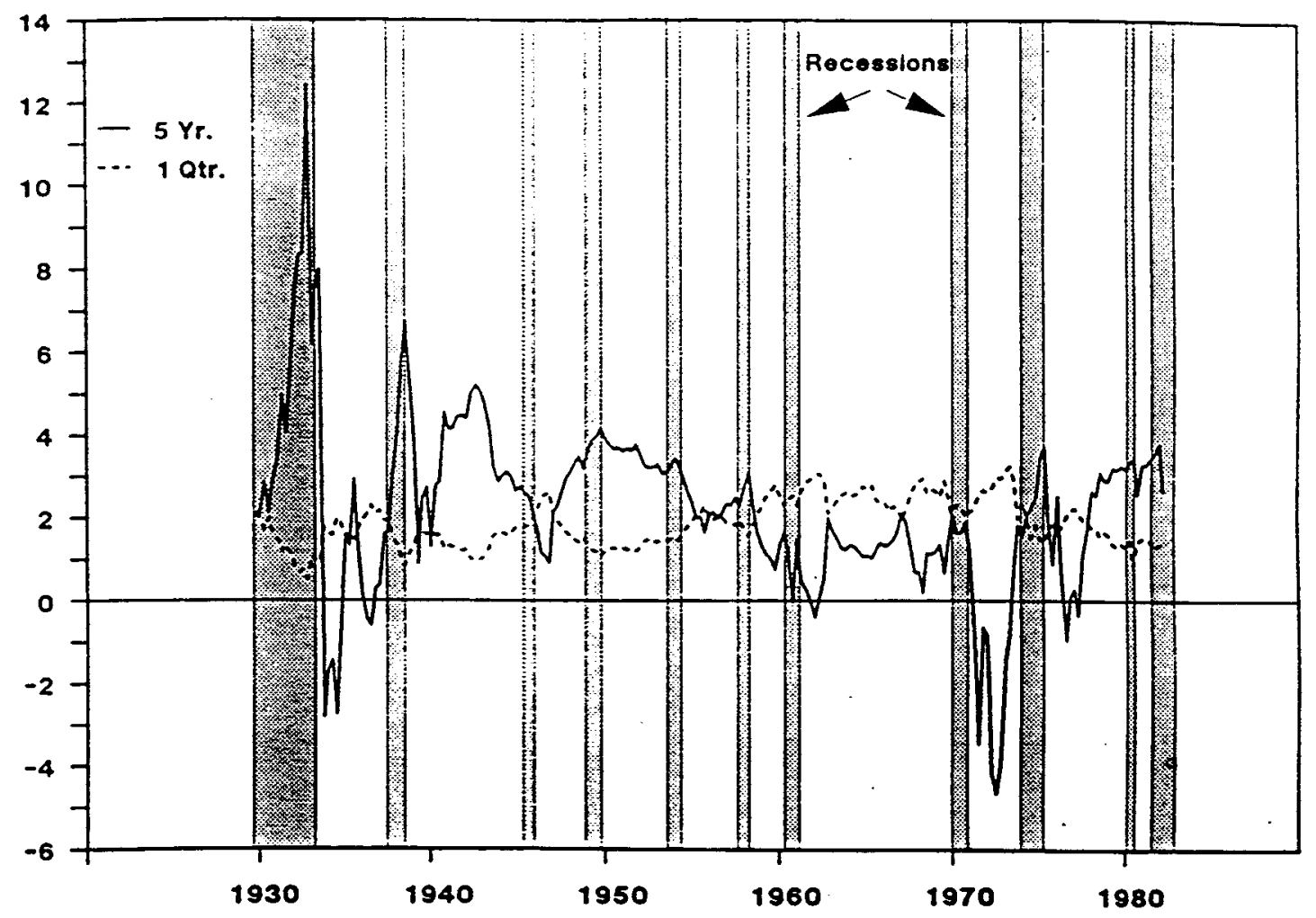

Figure 6. The estimated price of risk on the value-weighted portfolio of the New York Stock Exchange for investment horizons of one quarter (dashed line) and five years (solid line). The price of risk is the ratio of the estimated expected excess return to the square of the estimated standard deviation. 